$\begin{array}{cc}\text { ACADEMIA ROMÂNĂ } & \text { Rev. Roum. Chim., } \\ \text { 2021, 66(2), 161-166 } \\ \text { Revue Roumaine de Chimie } \\ \text { http://web.icf.ro/rrch/ }\end{array}$

\title{
THE STRUCTURE-ACTIVITY RELATIONSHIPS FROM DSC DATA
}

\author{
Adina Magdalena MUSUC ${ }^{\mathrm{a},{ }^{*}}$ and Dumitru OANCEA ${ }^{\mathrm{b}}$ \\ ${ }^{a}$ Roumanian Academy, "Ilie Murgulescu” Institute of Physical Chemistry, 202 Spl. Independentei, 060021 Bucharest, Roumania \\ ${ }^{b}$ Department of Physical Chemistry, University of Bucharest, 4-12 Regina Elisabeta Blvd, 030018 Bucharest, Roumania
}

The differential scanning calorimetry becomes nowadays an easily available technique able to provide experimental data which can be used to seek for possible correlations with molecular properties. Among these data, the entropy and enthalpy for different phase transition like melting or decomposition of various related compounds proved to be very fruitful. In the present paper, the enthalpy and entropy data for different phase transitions and decomposition of two classes of related energetic compounds (13 based on phenoxazone derivatives and 6 on substituted (E)-3-(azulen-1-yldiazenyl)1,2,5-oxadiazole) are analyzed and presented. The heats of decomposition seem to present no correlations as functions of molecular mass or melting temperature, while the heats of melting and the temperatures of melting present a fair correlation as a function of the molecular mass or melting temperature. A particularly good correlation is provided by the entropy of melting as a function of the enthalpy of melting, in accord with their significance for a process at equilibrium.

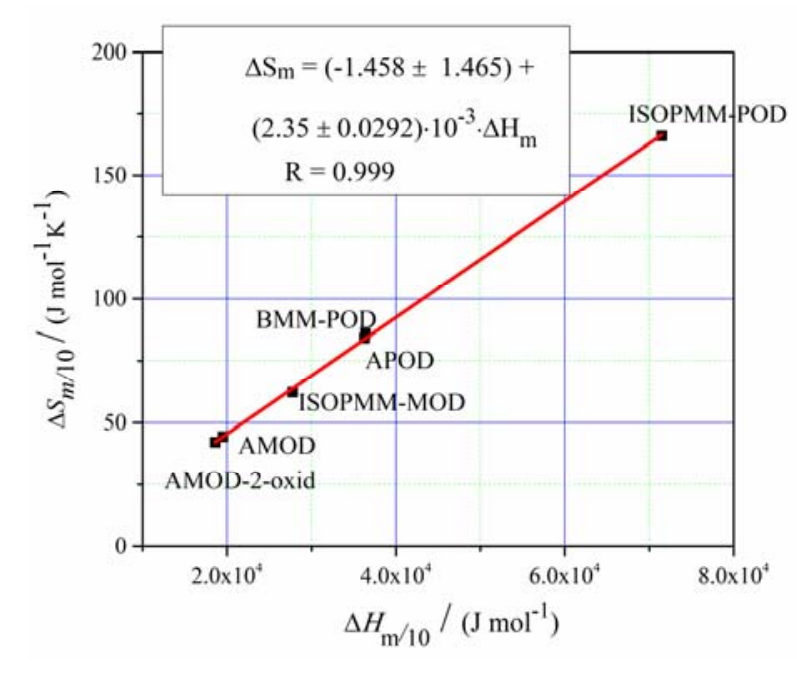

seminal works of A. T. Balaban. ${ }^{2-4}$ Some new works enlarged the knowledge in the field. ${ }^{5-9}$ The subsequent pertinent papers have been dedicated to the experimental methods allowing for the measurements of different thermal properties, especially those based on differential scanning calorimetry (DSC). DSC is a useful technique able to rapidly provide all the thermodynamic parameters of different compounds. ${ }^{10,11}$ The evaluation of quantitative structure-property relationship (QSPR) methods coupled with predictive methods (such as: molecular modeling methods, computer-assisted chemical risk

\footnotetext{
*Corresponding author: amusuc@icf.ro; musucadina@yahoo.com; Tel: +40-21-3121147.
} 
assessment) mainly used to predict physicochemical properties of energetic compounds are of a growing interest. ${ }^{12-15}$ The extensive structureproperties relationships between various physicochemical and structural parameters of different classes of energetic compounds was studied by different research groups. ${ }^{16-24}$ The main advantage of quantitative structure-property relationships consists in establishment of a new structural model between various physical and chemical properties and the chemical structure. Moreover, the quantitative structure-property relationship can be useful to explain and to determine the structural and chemical properties of new chemical compounds with related molecular structure. ${ }^{25}$

Present research is focused on the study of structure-properties relationship of two sets of related energetic compounds (i) 13 based on phenoxazone derivatives and (ii) 6 based on substituted (E)-3-(azulen-1-yldiazenyl)-1,2,5oxadiazole. The data (melting temperature $T_{\mathrm{m}}$, molar mass $M$, melting enthalpy $\Delta H_{\mathrm{m}}$, and enthalpy of decomposition $-\Delta H_{\text {dec }}$ ) used in these predictions are obtained from differential scanning calorimetry measurements, in our previous works. $^{26,27}$

\section{RESULTS AND DISCUSSION}

Figure 1 presents a typical DSC curve for (E)-3-(azulen-1-yldiazenyl)-4-phenyl-1,2,5oxadiazole (APOD) obtained in non-isothermal heating mode, at a $10 \mathrm{~K} \mathrm{~min}^{-1}$ heating rate. The physical parameters such as: melting temperature $\left(T_{\mathrm{m}}\right)$ and melting heat $\left(\Delta H_{\mathrm{m}}\right)$, maximum decomposition temperature $\left(T_{\max }\right)$ and decomposition heat $\left(-\Delta H_{\mathrm{dec}}\right)$ were obtained from the experimental DSC curve.

The stability of a molecule is quantified by the standard free energy $\Delta G$ with is the sum of two contributions according to equation (1):

$$
\Delta G(T)=\Delta H(T)-T \Delta S(T)
$$

where $\Delta H$ and $\Delta S$ are the enthalpy and the entropy changes at the temperature $T$ at which $\Delta G$ is being evaluated. At the melting point $\left(T=T_{\mathrm{m}}\right)$, the whole system being at equilibrium (when $\Delta G=0$ ), and equation (2) can be obtained:

$$
\Delta S_{m}=\frac{\Delta H_{m}}{T_{m}}
$$

Consequently, the melting entropy of studied compounds can be calculated using the eq. (2), where $T_{m}$ and $\Delta H_{m}$ are the temperature and heat of melting, and $\Delta S_{m}$ is the melting entropy. It is well known that both melting enthalpy and entropy are dependent on the chemical structure of compounds: the melting enthalpy is dependent on the intermolecular interaction between various functional groups of the molecule, whereas the melting entropy is dependent on the internal arrangement of the groups present in a molecule. ${ }^{14}$

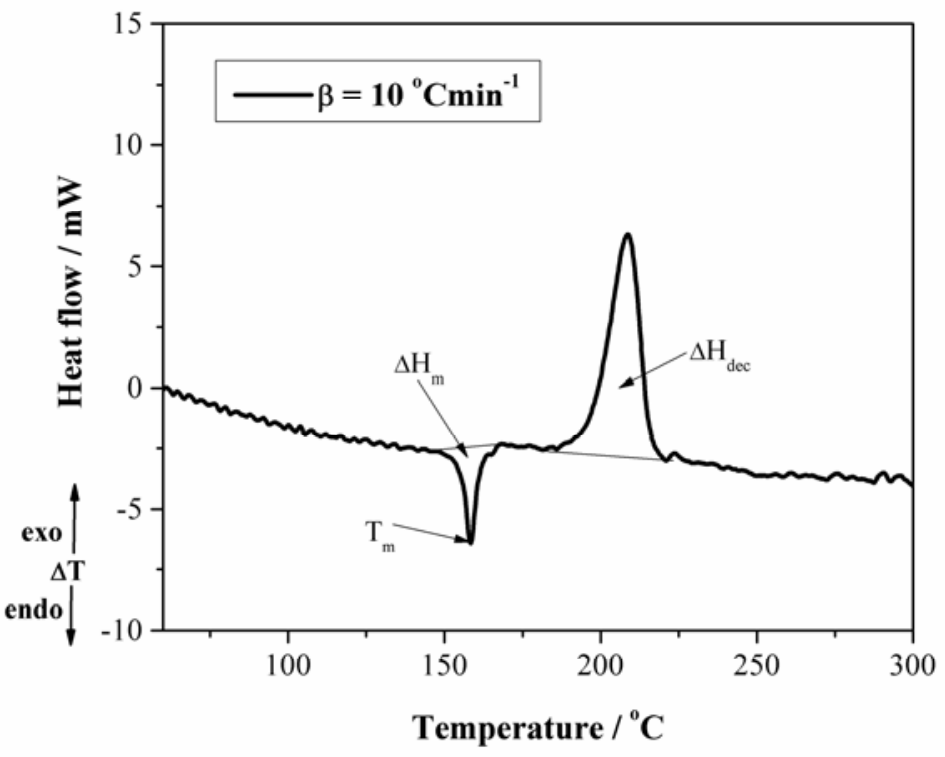

Fig. 1 - The DSC curve of (E)-3-(azulen-1-yldiazenyl)-4-phenyl-1,2,5-oxadiazole (APOD) decomposition, recorded at $10 \mathrm{~K} \mathrm{~min}^{-1}$ heating rate and ambient pressure. 


\section{RESULTS AND DISCUSSION}

The necessary data for study of structureproperties relationship (melting temperature $T_{\mathrm{m}}$, molar mass $M$, melting enthalpy $\Delta H_{\mathrm{m}}$, melting entropy $\Delta S_{\mathrm{m}}$ and enthalpy of decomposition $\Delta H_{\mathrm{dec}}$ ), obtained from prevoius studies ${ }^{26,27}$ are shown in Tables 1 and 2. Since the DSC data exhibit slight variations with heating rate, the same heating rate of $10 \mathrm{Kmin}^{-1}$ was used throughout.

In Figs. 2 and 3, the correlations between the decomposition heat of studied compounds and molar masses or melting temperatures were analyzed.

The heat of decomposition values of the substituted oxadiazoles does not show any regularity, as shown in Fig. 2. The number of studied oxodiazoles is too small to observe trends dependent on the molar masses. However, the effect of the nature of the substituents on both oxadiazole and azulenic cycles can be noticed. AMOD and ISOPMM-MOD have lower decomposition heats. The differences between the two compounds are given by the presence of isopropyl and two methyl groups on the azulenic cycles in the case of ISOPMM-MOD. In the middle, there are the compounds with a phenyl group on the oxodiazole cycle. The variation of $\Delta H_{\mathrm{dec}}$ in this series is: BMM-POD $<$ APOD $<$ ISOPMM-POD. Differences between them are attributed to the presence of iso-propyl, tert-butyl and methyl groups from the azulenic cycle.

Table 1

The DSC experimental data $\left(T_{\mathrm{m}}, \Delta H_{\mathrm{m}},-\Delta H_{\mathrm{dec}}\right)$, molar masses $(M)$, and calculated $\left(\Delta S_{\mathrm{m}}\right)$ for substituted $(E)$-3-(azulen-1-yldiazenyl)-1,2,5-oxadiazole), obtained at $10 \mathrm{~K} \mathrm{~min}^{-1}$ heating rate ${ }^{26}$

\begin{tabular}{c|c|c|c|c|c}
\hline Code & $\begin{array}{c}M \\
\left(\mathrm{~g} \mathrm{~mol}^{-1}\right)\end{array}$ & $\begin{array}{c}T_{\mathrm{m} / 10} \\
(\mathrm{~K})\end{array}$ & $\begin{array}{c}\Delta H_{\mathrm{m} / 10} \\
\left(\mathrm{~J} \mathrm{~mol}^{-1}\right)\end{array}$ & $\begin{array}{c}\Delta S_{\mathrm{m} / 10} \\
\left(\mathrm{~J} \mathrm{~mol}^{-1} \mathrm{~K}^{-1}\right)\end{array}$ & $\begin{array}{c}-\Delta H_{\mathrm{dec}} \\
\left(\mathrm{J} \mathrm{mol}^{-1}\right)\end{array}$ \\
\hline APOD & 300 & 431.5 & 36285 & 84.1 & 682.0 \\
BMM-POD & 384 & 423.8 & 36426 & 86.0 & 508.1 \\
ISOPMM-POD & 370 & 430.2 & 71503 & 166 & 772.9 \\
AMOD & 238 & 444.1 & 19530 & 44.4 & 325.7 \\
ISOPMM-MOD & 308 & 446.1 & 27784 & 62.23 & 247.26 \\
AMOD-2-oxid & 254 & 442.9 & 18621 & 42.1 & 826.49 \\
\hline
\end{tabular}

Notation: APOD - (E)-3-(azulen-1-yldiazenyl)-4-phenyl-1,2,5-oxadiazole; BMM-POD - (E)-3-((6-tert-butyl-4,8-dimethylazulen-1yl) diazenyl)-4-phenyl-1,2,5-oxadiazole; ISOPMM-POD - (E)-3-((5-iso-propyl-3,8-dimethylazulen-1-yl) diazenyl)-4-phenyl-1,2,5oxadiazole; AMOD - (E)-3-(azulen-1-yldiazenyl)-4-methyl-1,2,5-oxadiazole; ISOPMM-MOD - (E)-3-((5-iso-propyl-3,8dimethylazulen-1-yl) diazenyl)-4-methyl-1,2,5-oxadiazole; AMOD-2-oxid - (E)-4-(azulen-1-yldiazenyl)-3-methyl-1,2,5-oxadiazole2 oxide.

Table 2

The DSC experimental data $\left(T_{\mathrm{m}}, \Delta H_{\mathrm{m}},-\Delta H_{\mathrm{dec}}\right)$, molar masses $(M)$, and calculated $\left(\Delta S_{\mathrm{m}}\right)$ for phenoxazone derivatives at $10 \mathrm{~K} \mathrm{~min}^{-1}$ heating rate ${ }^{27}$

\begin{tabular}{c|c|c|c|c|c}
\hline Code & $\begin{array}{c}M \\
\left(\mathrm{~g} \mathrm{~mol}^{-1}\right)\end{array}$ & $\begin{array}{c}T_{\mathrm{m} / 10} \\
(\mathrm{~K})\end{array}$ & $\begin{array}{c}\Delta H_{\mathrm{m} / 10} \\
\left(\mathrm{~kJ} \mathrm{~mol}^{-1}\right)\end{array}$ & $\begin{array}{c}\Delta S_{\mathrm{m} / 10} \\
\left(\mathrm{~J} \mathrm{~mol}^{-1} \mathrm{~K}^{-1}\right)\end{array}$ & $\begin{array}{c}-\Delta H_{\mathrm{dec}} \\
\left(\mathrm{kJ} \mathrm{mol}^{-1}\right)\end{array}$ \\
\hline AA-Ho & 224.17 & 448.0 & 13.5 & 30.1 & 312 \\
PA-Ho & 238.203 & 426.0 & 26.3 & 62.1 & 362 \\
BA-Ho & 286.247 & 513.6 & 52.38 & 102 & 326 \\
$4 \mathrm{CH}_{3}$-BA-Ho & 331.244 & 515.6 & 53.9 & 104.5 & 366 \\
$2 \mathrm{NO}_{2}$-BA-Ho & 300.274 & 522.7 & 20.7 & 28.1 & 533 \\
$4 \mathrm{CH}_{3} \mathrm{O}-$-BA-Ho & 316.273 & 524.0 & 16.51 & 21.2 & 399 \\
3NO $\mathrm{NO}_{2}$-BA-Ho & 331.244 & 568.0 & 30.9 & 54.4 & - \\
$4 \mathrm{NO}_{2}$-BA-Ho & 331.244 & 600.0 & 13.5 & 22.5 & - \\
Ac-Ho & 238.203 & 398.0 & 33.5 & 84.2 & 189 \\
Met-Et-Ket-Ho & 252.23 & 386.0 & 32.4 & 84.1 & 353 \\
AcPhen-Ho & 300.274 & 521.0 & 51.6 & 98.9 & 363 \\
5Cy-Ho & 264.241 & 419.0 & 31.3 & 74.7 & 436 \\
6Cy-Ho & 278.268 & 436.0 & 40.1 & 92.3 & 440 \\
\hline
\end{tabular}

Notation: $\mathrm{Ho}=2$, 4-dinitrophenylhydrazone; $\mathrm{AA}=$ acetaldehyde; $\mathrm{PA}=$ propionaldehyde; $\mathrm{BA}=$ benzaldehyde; $\mathrm{Ac}=$ acetone; Met-Et-Ket = methyl ethyl ketone; AcPhen = acetophenone; $5 \mathrm{Cy}=$ cyclopentanone; $6 \mathrm{Cy}=$ cyclohexanone 

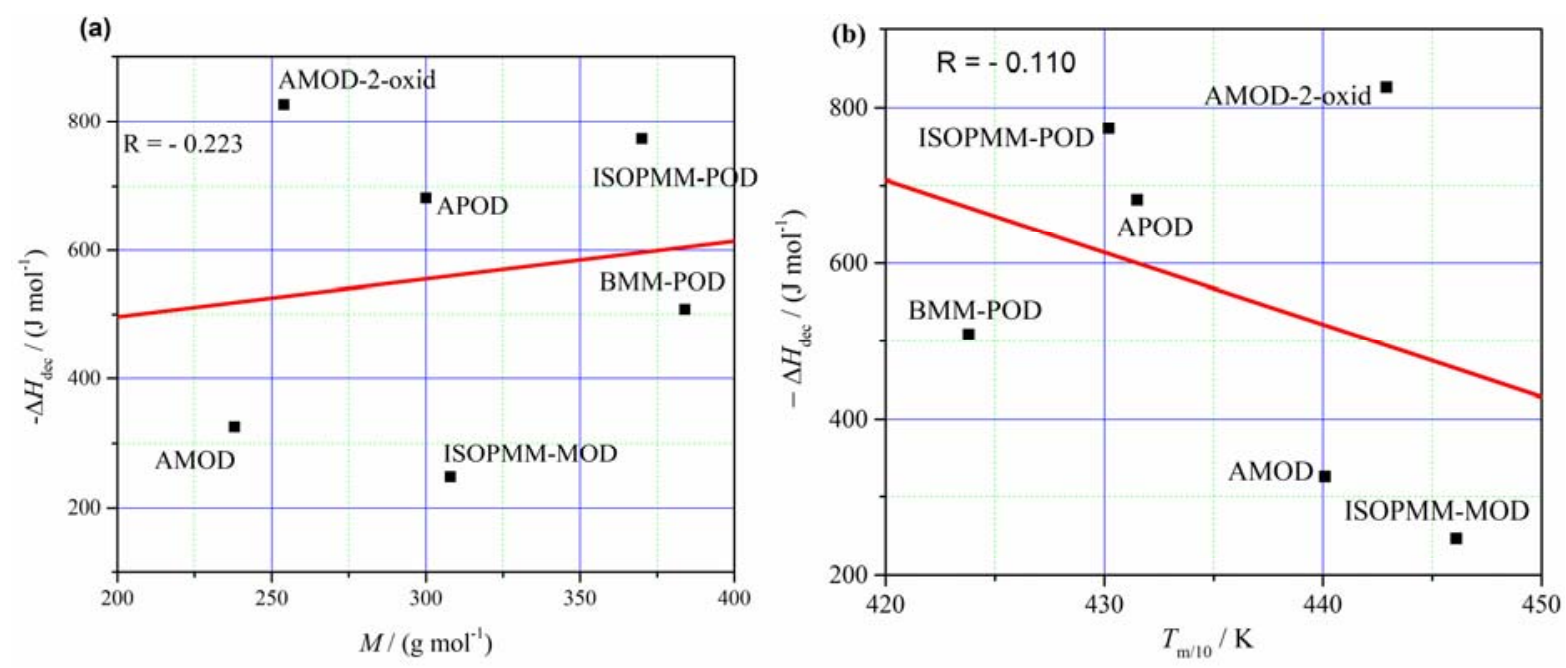

Fig. 2 - (a) $-\Delta H_{\text {dec }} v s . M$ and (b) $-\Delta H_{\text {dec }} v s . T_{\mathrm{m} / 10}$ for the substituted (E)-3-(azulen-1-yldiazenyl)-1,2,5-oxadiazole.
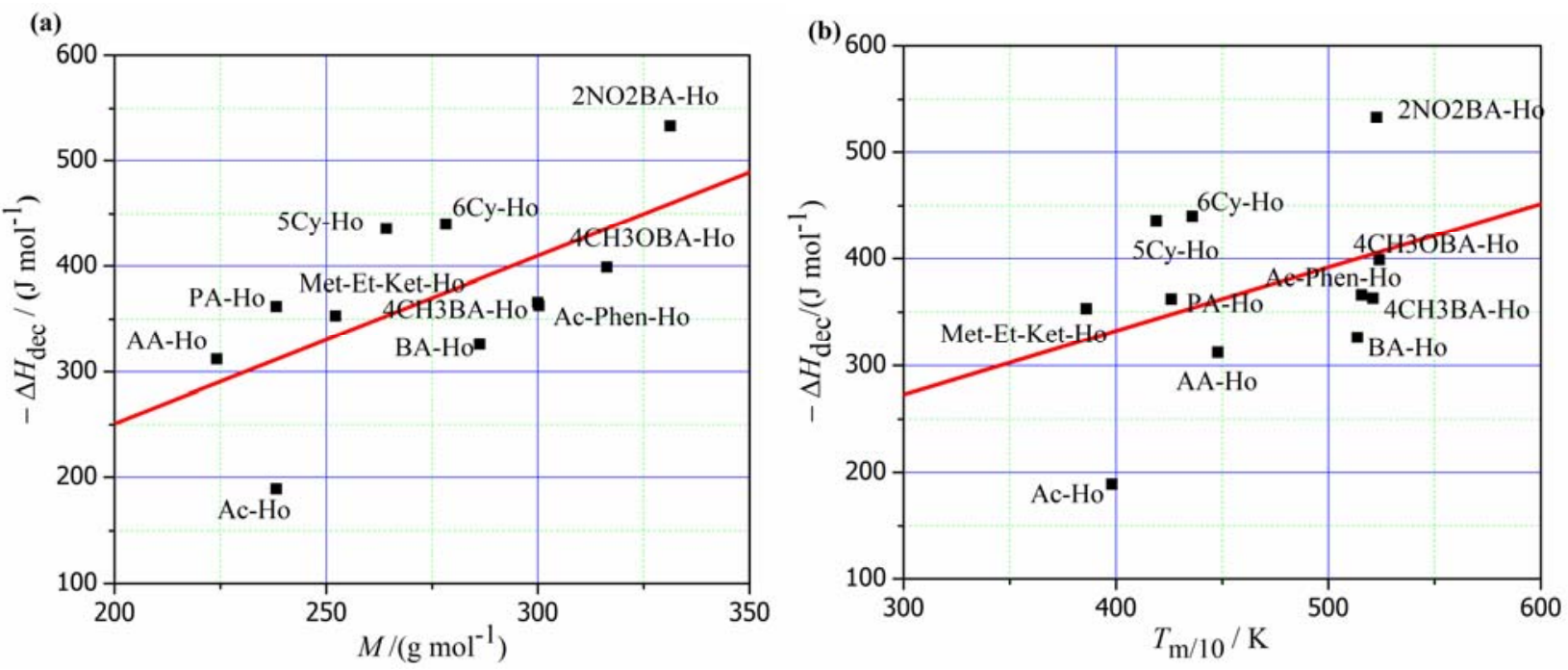

Fig. 3 - (a) $-\Delta H_{\text {dec }} v s . M$ and (b) $-\Delta H_{\text {dec }} v s . T_{\mathrm{m} / 10}$ for the phenoxazone derivatives.

For the phenoxazone derivatives one may notice a slight linear correlation between the heat of decomposition and the molar mass, according to

$$
\Delta H_{d e c}\left(k J \cdot \mathrm{mol}^{-1}\right)=-67.34+1.591 M\left(\mathrm{~g} \cdot \mathrm{mol}^{-1}\right)
$$

Correlation with the melting temperatures (Fig. 3b) is practically non-existent according to equation (4):

$$
\Delta H_{d e c}\left(k J \cdot \mathrm{mol}^{-1}\right)=94.06+0.596 T_{m}(K)
$$

which indicates a correlation coefficient $R=0.048$.

Analyzing the data presented in Fig. 4(a) points to a slight linear correlation between melting heat 1,2,5-oxadiazole and the molar mass according to equation (5): equation (3), with a correlation coefficient $R=$ 0.345 (Fig. 3a): of the substituted (E)-3-(azulen-1-yldiazenyl)-

$$
\Delta H_{m / 10}\left(\mathrm{~J} \cdot \mathrm{mol}^{-1}\right)=-41430.31+247.42 \times M\left(\mathrm{~g} \cdot \mathrm{mol}^{-1}\right)
$$

with a correlation coefficient $R=0.456$. On the other hand, as seen in Fig. $4 \mathrm{~b}$, the melting heat presents no correlation with the melting temperature. 

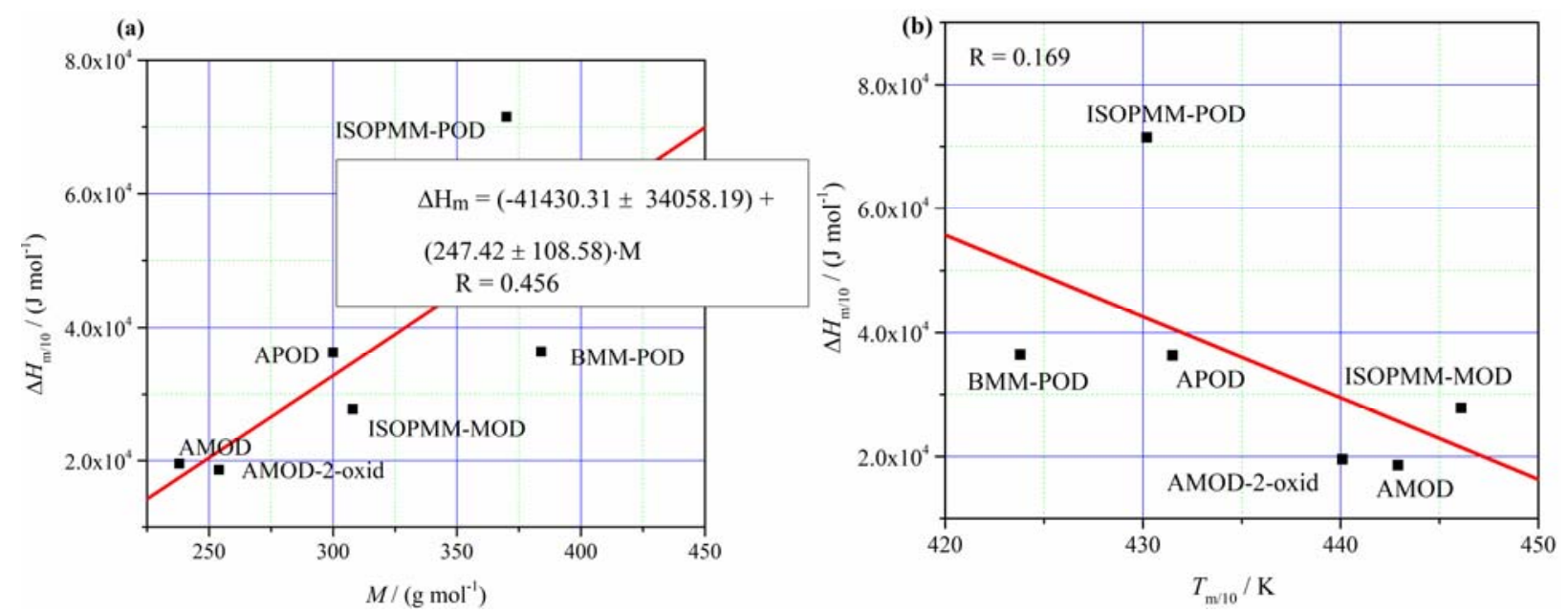

Fig. 4 - (a) $\Delta H_{\mathrm{m} / 10} v s . M$ and (b) $\Delta H_{\mathrm{m} / 10}$ vs. $T_{\mathrm{m} / 10}$ for the substituted (E)-3-(azulen-1-yldiazenyl)-1,2,5-oxadiazole.
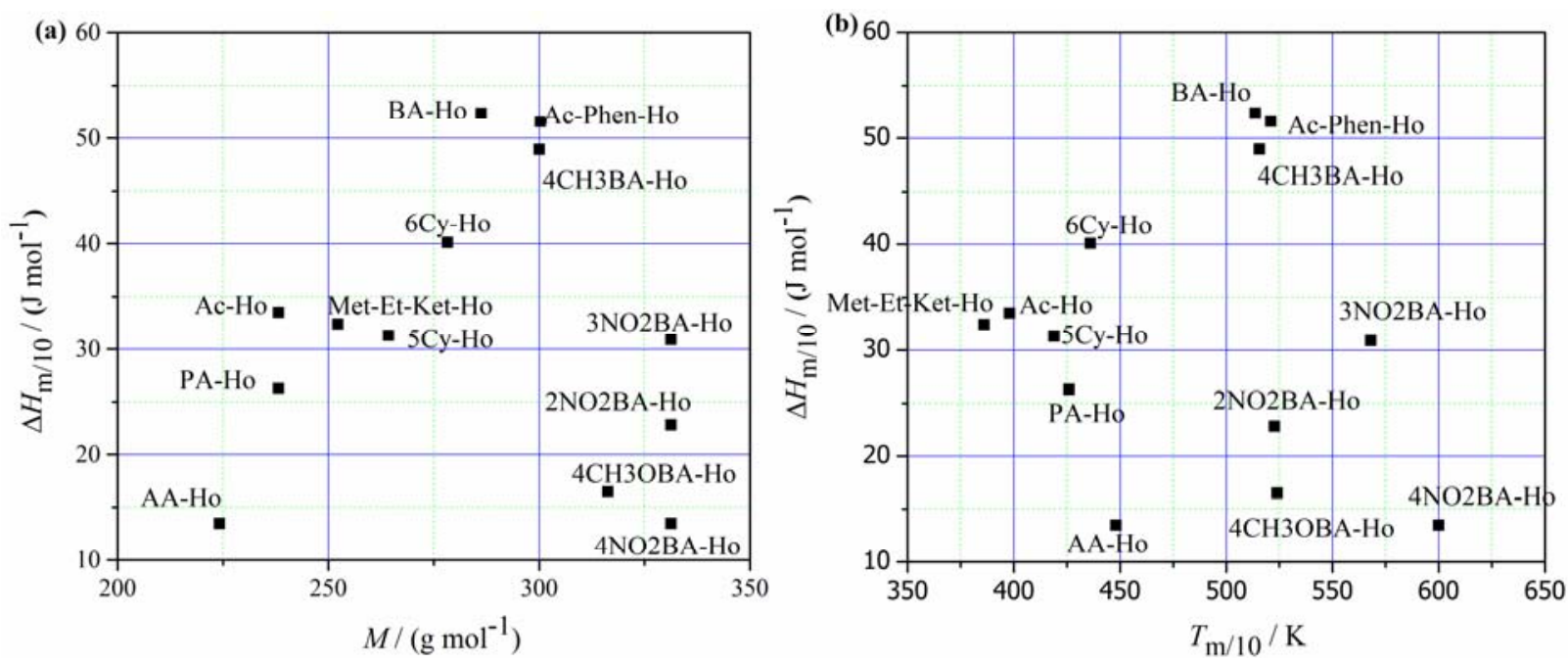

Fig. 5 - (a) $\Delta H_{\mathrm{m} / 10} v s . M$ and (b) $\Delta H_{\mathrm{m} / 10} v s . T_{\mathrm{m} / 10}$ for the phenoxazone derivatives.
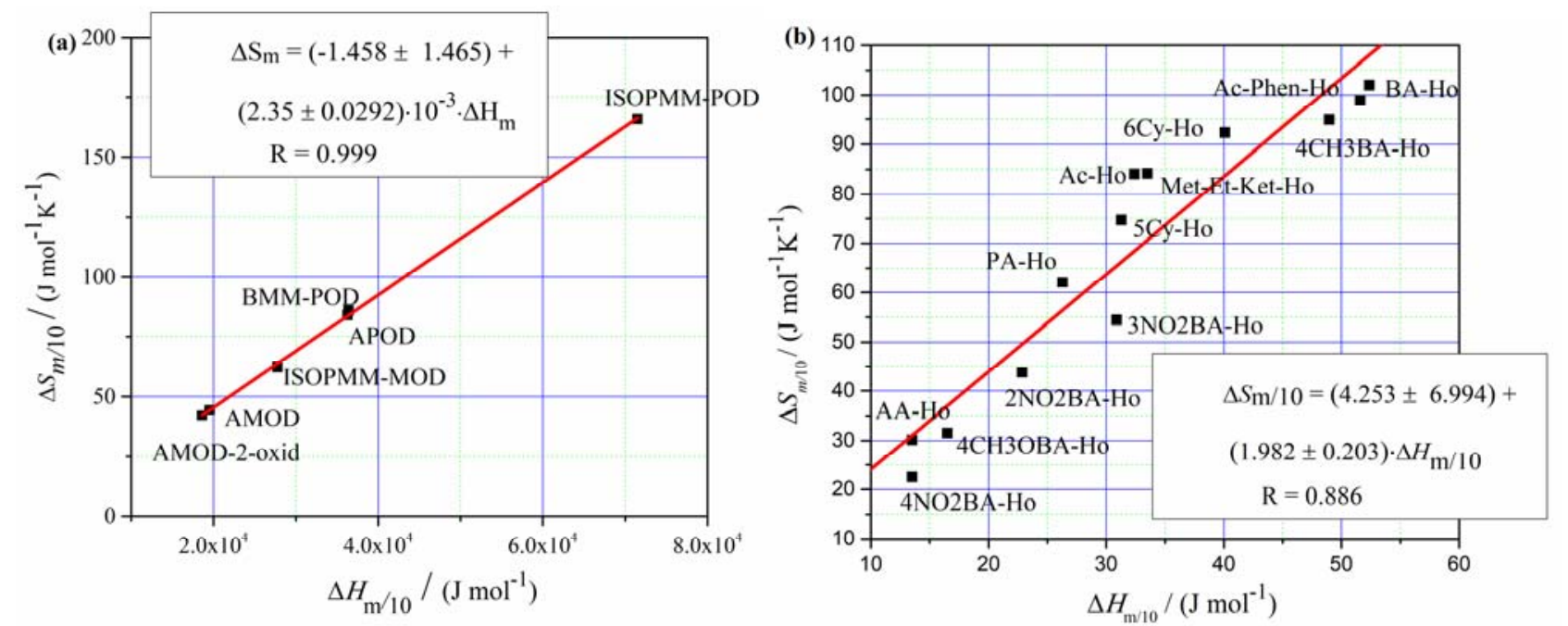

Fig. $6-\Delta H_{m / 10}$ versus $\Delta S_{m / 10}$ plot for (a) the substituted (E)-3-(azulen-1-yldiazenyl)-1,2,5-oxadiazole and (b) the phenoxazone derivatives.

Figure 5 depicts the melting heat of phenoxazone derivatives as a function of their molar masses or melting temperatures. No correlation can be inferred from data presented. 
A statistically significant trend was found between $\Delta H_{m / 10}$ determined experimentally and calculated $\Delta S_{m / 10}$ from the equilibrium relationship $\Delta G_{m}=0$. Analyzing the data from Fig. 6 linear correlations were obtained according to equation (6) for the substituted oxodiazoles, and according to equation (7) for the phenoxazone derivatives, respectively:

$$
\Delta S_{m / 10}\left(J \cdot m o l^{-1} K^{-1}\right)=-1.458+2.35 \times 10^{-3} \times \Delta H_{m / 10}\left(J \cdot m o l^{-1}\right)
$$

with a correlation coefficient $\mathrm{R}=0.999$;

$$
\Delta S_{m / 10}\left(J \cdot \mathrm{mol}^{-1} \mathrm{~K}^{-1}\right)=4.253+1.982 \times \Delta H_{m / 10}\left(\mathrm{~J} \cdot \mathrm{mol}^{-1}\right)
$$

with a correlation coefficient $\mathrm{R}=0.886$.

\section{CONCLUSIONS}

The available experimental DSC data for two classes of related energetic compounds ( 6 based on substituted (E)-3-(azulen-1-yldiazenyl)-1,2,5oxadiazole and 13 on phenoxazone derivatives have been systematized and critically evaluated. The present study is a first attempt to investigate if the heat of melting $\left(\Delta H_{\mathrm{m}}\right)$ and heat of decomposition $\left(\Delta H_{\mathrm{dec}}\right)$ of these compounds correlate with their molar masses and/or melting points. For the substituted (E)-3-(azulen-1yldiazenyl)-1,2,5-oxadiazole, there are no correlations between the heats of decomposition as a function of either molar masses or the melting temperatures. There is a slight correlation for the phenoxazone derivatives.

A definite linear correlation between the entropy of melting and the enthalpy of melting was found for both classes of energetic compounds. This can be used to assess some thermodynamic and physical properties of related compounds (e.g. the heat of decomposition, the bond dissociation energy, the activation energy) using only a single energetic parameter, meaning $\Delta H_{\mathrm{m}}$. Subsequently, this correlation between the two parameters can be further used to evaluate the relationship between physico-chemical properties and the structural characteristics of similar energetic compounds (e.g. nitroaromatic compounds, particularly nitrobenzene derivatives).

\section{REFERENCES}

1. A. T. Balaban, I. Motoc, D. Bonchev and O. Mekenyan, "Topological indices for structure-activity correlations", in "Steric Effects in Drug Design. Topics in Current Chemistry", vol 114. Springer, Berlin, Heidelberg, 1983.

2. A. T. Balaban (Ed.), "Chemical Applications of Graph Theory" Academic Press, London, 1976.
3. A. T. Balaban, A. Chiriac, I. Motoc and Z. Simon, "Steric Fit in Quantitative Structure Activity Relations", Lecture Notes in Chemistry No. 15, Springer Verlag, Berlin, 1980.

4. A. T. Balaban, M. Banciu and I. Pogany, "Aplicații ale metodelor fizice în chimia organică”, Editura Ştiințifică şi Enciclopedică, Bucureşti, 1983.

5. S. V. Mani, D. W. Connell and R. D. Braddock, Crit. Rev. Environ. Control, 1991, 21, 217-236.

6. H. E. Kissinger, J. Res. Natl. Bur. Stand., 1956, 57, 217-221.

7. A. N. Veselkov, V. Ya. Maleev, E. N. Glibin, L. Karawajew and D. B. Davies, Eur. J. Biochem., 2003, $270,4200-4207$.

8. K. K. Arthur, N. Dinh and J. P. Gabrielson, J. Pharm. Sci., 2015, 104, 1548-1554.

9. N. Tirelli, U. W. Suter, A. Altomare, R. Solaro, F. Ciardelli, S. Follonier, Ch. Bosshard and P. Günter, Macromolecules, 1998, 31, 2152-2159.

10. A. M. Musuc, D. Razus and D. Oancea, J. Therm. Anal. Calorim., 2009, 98, 779-784.

11. J. Pandele Cusu, A. M. Musuc and D. Oancea, J. Therm. Anal. Calorim., 2012, 109, 123-129.

12. G. Fayet, P. Rotureau, L. Joubert and C. Adamo, Process Saf. Prog., 2010, 29, 359-371.

13. K. V. Zherikova and S. P. Verevkin, J. Therm. Anal. Calorim., 2019, 138, 4045-4059.

14. S. H. Yalkowsky, J. Pharm . Sci., 2014, 103, 2629-2634.

15. M. Reichel, D. Dosch, T. Klapötke and K. Karaghiosoff, J. Am. Chem. Soc., 2019, 141, 19911-19916.

16. M. J. Kamlet and H. G. Adolph, Propellants Explos. Pyrotech., 1979, 4, 30-34.

17. M. J. Kamlet, ONR Report ACR 221, San Diego, CA, USA, 1976.

18. S. Zeman, Propellants Explos. Pyrotech., 1992, 17, 17-19.

19. S. Zeman, Thermochim. Acta, 1993, 216, 157-168.

20. S. Zeman, Propellants Explos. Pyrotech., 2000, 25, 66-74.

21 S. Zeman and M. Krupka, Propellants Explos. Pyrotech., 2003, 28, 301-307.

22. S. Zeman and M. Krupka, Propellants Explos. Pyrotech., 2003, 28, 249-255.

23. X. S. Song, X. L. Cheng and X. D. Tang, Propellants Explosiv. Pyrotech., 2006, 31, 306-309.

24. B. Tan, X. Long, R. Peng, H. Li, B. Jin and S. Chu, J. Phys. Chem. A, 2011, 115, 10610-10616.

25. O. Ivanciuc, T. Ivanciuc and A. T. Balaban, Internet Electron. J. Mol. Des., 2002, 1, 252-268.

26. A. M. Musuc, L. Birzan, M. Cristea, D. Razus, A. Razus and D. Oancea, J. Therm. Anal. Calorim., 2020 https://doi.org/10.1007/s10973-020-10164-5.

27. J. Pandele Cusu, A. M. Musuc and D. Oancea, Thermochim. Acta, 2020, 689, 178610. 